\title{
Riqueza e distribuição temporal de anuros (Amphibia: Anura) em um fragmento de Floresta Ombrófila Mista
}

\author{
Eduardo J. Santos ${ }^{1} \&$ Carlos E. Conte ${ }^{1,2}$
}

1. Departamento de Zoologia, Universidade Federal do Paraná, Caixa Postal 19020, 81531-980 Curitiba, PR, Brasil. (ejs.1988@yahoo.com.br)

2. Instituto Neotropical: Pesquisa e Conservação, Caixa Postal 19009, 81531-980, Curitiba, PR. (kadu_conte@yahoo.com.br)

RESUMO. Apesar do Brasil abrigar uma riqueza elevada de anfíbios anuros, muitas regiões ainda são consideradas subamostradas, incluindo ecossistemas que estão degradados e ameaçados. Esse é o caso da Floresta Ombrófila Mista (FOM), formação que possui apenas 3\% de sua distribuição original, sendo que apenas uma porcentagem menor ainda constitui florestas em estágio primário ou avançado. O objetivo deste estudo foi determinar a estrutura de uma taxocenose de anuros em um remanescente de FOM, avaliar a variação de riqueza e abundância em função de variáveis climáticas, comparar a taxocenose com outras oito inseridas na mesma formação e verificar se a riqueza registrada nas localidades varia em função da área total, da quantidade ou dos tipos de ambientes presentes. Foram realizadas 12 campanhas entre setembro de 2008 e agosto de 2009, totalizando 72 horas de amostragem. Por meio dos métodos de amostragem em sítio de reprodução em sete corpos d'água e de busca aural em quatro transecções no interior da floresta, foi registrada a ocorrência de 24 espécies de sete famílias, correspondendo a $96 \%$ da riqueza estimada para a área. Tanto a riqueza quanto a abundância foram registradas no período com maior volume de chuva. O número de espécies nos ambientes amostrados variou de um a 15, e quase metade (41\%) delas foram exclusivas de ambientes florestais. Para os inventários de anuros em FOM, o que explica a maior riqueza de espécies é a quantidade de tipos de ambientes amostrados, indicando que amostragens em localidades mais heterogêneas, que podem satisfazer os requisitos reprodutivos de um maior número de espécies, aumentam o registro da riqueza local. Mesmo sendo um fragmento pequeno e alterado, a riqueza registrada foi alta se comparada com outras áreas cuja anurofauna foi inventariada, e que estão inseridas na FOM e apresentam esforço amostral semelhante. Devido à ocorrência de muitas espécies dependentes da integridade da floresta a minimização de atividades antrópicas e estudos mais detalhados devem ser as principais diretrizes para a manutenção e conservação local.

PALAVRAS-CHAVE. Anfíbios, anurofauna, floresta com araucária, heterogeneidade ambiental, inventário.

\begin{abstract}
Richness and temporal distribution of anurans (Amphibia: Anura) in a Mixed Ombrophile Forest fragment. In spite of harboring high richness of anuran amphibians, Brazil still has many regions considered to be undersampled, including ecosystems which are degraded and threatened. This is the case of the Mixed Ombrophile Forest (FOM), a formation which has only $3 \%$ of its original vegetation, and an even smaller percentage of it constitutes forests in primary or advanced stages. The objective of the present study was to determine the structure of an assemblage of anurans in a remnant of the Mixed Ombrophile Forest, comparing that assemblage with 8 other assemblages known to occur in localities in the Mixed Ombrophile Forest formation, and to verify if the richness of each local varies according to the quantity or types of sites sampled in each inventory. A total of twelve campaigns were carried out from September 2008 to August 2009 to sample 11sites, totaling 72 sampling hours. Through the methods of sampling at breeding sites in seven sites and aural search in four transects, the occurrence of 24 species from seven families was registered, corresponding to $96 \%$ of the estimated richness in the area $(\mathrm{n}=25)$. Both richness and specific abundance were registered in the wettest period. The number of species in the sites varied from one to 15, and almost half (41\%) of them were exclusive of forest environment. The most important variable for the register of a higher number of species in the present study and other areas inside FOM was the quantity of types of sampled sites, and not the area size and total number of habitats, indicating that sampling in heterogeneous environments, which may harbor more reproductive modes for anurans, enhance local richness registers. Despite being a small and altered fragment, the observed richness was high if compared to other areas whose anurofauna was inventoried inside the araucaria forest domain, with a similar sampling effort. Due to occurrence of many species dependent on the integrity of the forest, the minimization of anthropic activities and more detailed studies must be the main goals for their maintenance and local conservation.
\end{abstract}

KEYWORDS. Amphibians, anurofauna, araucaria forest, environmental heterogeneity, inventory.

Em taxocenoses de anfíbios anuros, os padrões de diversidade e dinâmica podem ser afetados por diferentes fatores, como a distribuição e dispersão das espécies, variações temporais e competição intra e interespecífica (Duellman \& Trueb, 1986; Bertoluci, 1998; Duellman, 1999; Azevedo-Ramos \& Galatti, 2002; Wells, 2007; Keller et al., 2009). O primeiro passo para o melhor entendimento do funcionamento desses processos é a realização de inventários e monitoramentos (Afonso \& Eterovick, 2007; CunHa et al., 2010), pois fornecem a base de dados que permite a comparação entre diferentes áreas e a realização de estudos mais detalhados, como a influência da heterogeneidade ambiental ou da variação climática sobre a diversidade (HeYer et al.,1994; SiLvano
\& Pimenta, 2003; Begon et al., 2007).

Apesar de sua importância, a determinação da composição de espécies e da diversidade em uma área podem ser difíceis de serem identificadas corretamente, dada a variação de complexidade das relações ecológicas em que cada táxon está inserido (Ricklefs \& Schluter, 1993; Chesson, 2000; Werner et al., 2007; Gotelli et al., 2009). No caso dos anfíbios anuros, correlações positivas têm sido encontradas tanto entre riqueza e fatores bióticos, como por exemplo, a competição direta por recursos com espécies invasoras (Pearl et al., 2004) e a predação de girinos por espécies de peixes (PIlliod et al., 2010) quanto por fatores abióticos, como por exemplo a fragmentação florestal (Bell \& Donnely, 2006) e a heterogeneidade 
ambiental (KeLLER et al., 2009).

Além disso, deve-se levar em consideração a perceptível necessidade e urgência para a realização de novos estudos, especialmente para regiões com histórico de intensa destruição de áreas naturais e de pouca geração de conhecimento ecológico (Silvano \& Segalla, 2005; ETEROVICK et al., 2005).

Esse é o caso da Floresta Ombrófila Mista (FOM), que foi alterada devido a atividades antrópicas por décadas, e que possui diversos fragmentos onde pouco, ou nada, se sabe quanto a diversidade e dinâmica das populações de anfíbios anuros (Conte \& Rossa-Feres, 2007). Seu estado de conservação atual é preocupante, pois a área atualmente florestada está reduzida e alterada em diferentes níveis (CAstella \& Britez, 2004) e também é um dos ecossistemas que detém menor número de áreas protegidas (MMA, 2012). Mesmo com um cenário desfavorável, a diversidade potencial para a FOM é alta, tendo como exemplo o aumento no número de descrições de espécies e novas ocorrências nos últimos anos (CONTE et al., 2010). Além disso, fragmentos florestais, mesmo que alterados, são importantes para fornecer os recursos necessários para a manutenção das espécies de anfíbios anuros, inclusive as que ocupam áreas abertas, pois os fragmentos podem funcionar como abrigo e corredores para outros ambientes de reprodução, alimentação, hibernação e estivação (Stebbins \& Cohen, 1995; Weyrauch \& Grubb JR, 2004; Zug et al., 2001).

O declínio de populações de anfíbios e suas conseqüências ecológicas têm sido evidenciadas nos últimos anos, tanto em escalas globais (HoulaHAN et al., 2000) quanto locais (GraY et al. 2004). Apesar de existirem diversos fatores agravando essa situação (ver revisão em BLAUSTEIN \& KIESECKER, 2002), a perda ou fragmentação de habitat tem sido considerada o mais impactante, principalmente para espécies dependentes de microhabitat e microclimas florestais específicos (BERTOLUCI et al., 2007), como por exemplo as espécies Xenohyla truncata (Rocha et al., 2005) e Scinax alcatraz (IUCN, 2012). Considerando o histórico de degradação e fragmentação da FOM, é sensato considerar a possibilidade de que algumas populações estejam sofrendo - ou já tenham sofrido - processo de declínio, ou ainda que tenham desaparecido por completo (Beebee \& Griffiths, 2005; Haddad \& Prado, 2005).

Partindo do princípio de que entender os padrões de diversidade e distribuição das populações de anuros é essencial para a tomada de decisões conservacionistas (Silvano \& Segalla, 2005; Eterovick et al., 2005), o presente trabalho tem como objetivos: i) descrever a composição, a riqueza e a distribuição temporal da taxocenose de anfíbios anuros ocorrentes em um fragmento de FOM, ii) comparar a riqueza encontrada com outras taxocenoses estudadas na FOM e iii) verificar a variação na riqueza entre essas taxocenoses em função do tamanho da área, do número e tipos de ambientes amostrados.

\section{MATERIAL E MÉTODOS}

Área de estudo. O estudo foi realizado no Parque

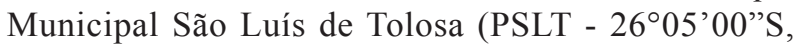
$49^{\circ} 48^{\prime} 05^{\prime}$ 'O), localizado no município de Rio Negro, sudeste do estado do Paraná (Fig. 1). A altitude é de 793 metros e o clima é subtropical úmido mesotérmico $(\mathrm{Cfb}$ de Köppen), com temperatura média de $18^{\circ} \mathrm{C}$, precipitação média anual de $1.600 \mathrm{~mm}$ e ocorrência de geadas frequentes e fortes no inverno (Rio Negro, 2004). O PSLT é um fragmento florestal de 53,8 ha, em estágio médio de sucessão, com alterações causadas por efeito de borda,

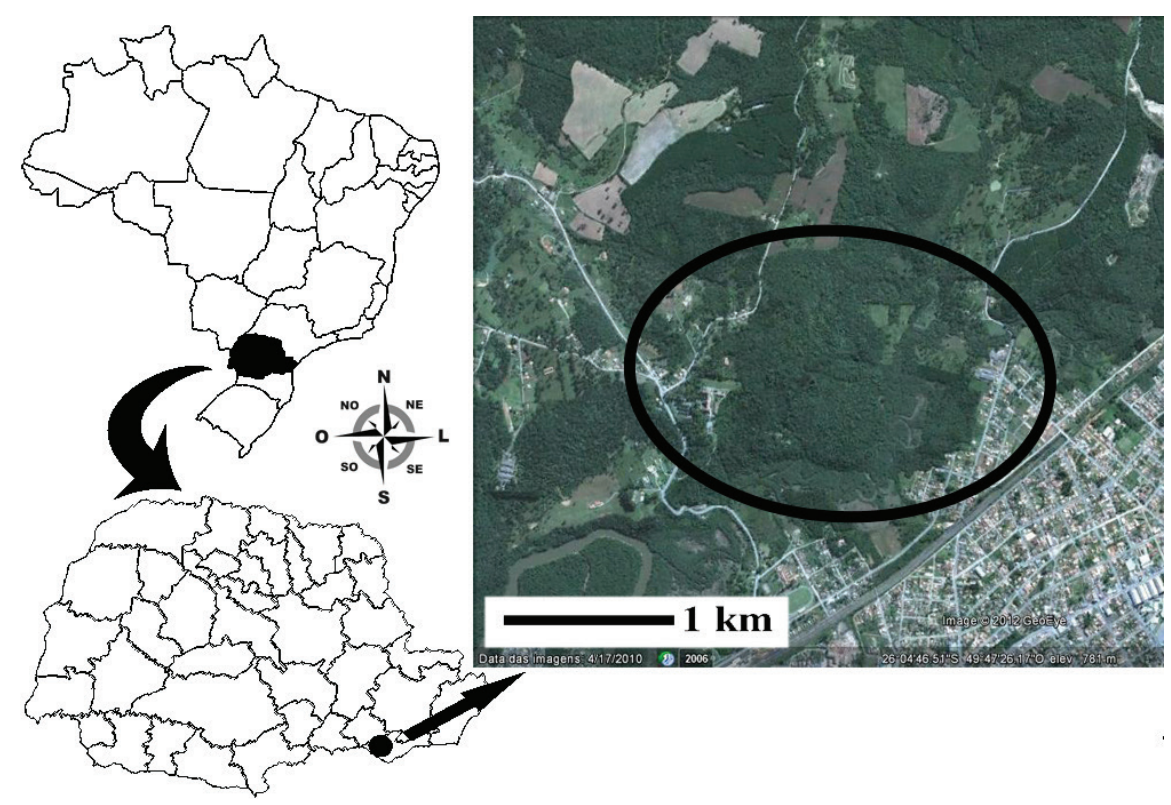

Fig. 1. Imagem aérea e localização do Parque Municipal São Luís de Tolosa, Rio Negro, PR ( $26^{\circ} 05^{\prime} 00^{\prime \prime}$, $49^{\circ} 48^{\prime} 05^{\prime}$ 'W), com ampliação do estado do Paraná, sul do Brasil. Imagem: Google Earth. 
trilhas, pressão antrópica e reflorestamento de Pinus em seu entorno (Rio Negro, 2004).

O fragmento está inserido na FOM, um ecossistema que faz parte do bioma Mata Atlântica (RoDERJAN et al., 2002; IBGE, 2004) e que ocupava originalmente $40 \%$ do estado do Paraná e se estende do extremo sul do estado de São Paulo até a porção central do estado do Rio Grande do Sul (MAack, 1981; Veloso et al., 1991; IBGE, 2004). Esse ecossistema, assim como outros no Brasil, passou por um intenso processo de degradação e fragmentação causado pela urbanização, pelo corte seletivo de madeira e pela expansão agropecuária (CASTELLA \& BRITEZ, 2004), o que reduziu a distribuição da floresta à cerca de $3 \%$ da cobertura original, sendo que apenas a menor parte desse percentual compõe florestas em estágio primário ou avançado.

Coleta de dados. Foram realizadas 12 campanhas com frequência mensal ao campo, entre setembro de 2008 e agosto de 2009, totalizando 72 horas durante o estudo. Em cada fase, os anuros adultos de onze ambientes (dois açudes em borda florestal, um açude em área aberta, um açude e uma poça temporária no interior de floresta, duas transecções em riachos, uma transecção paralela a um rio e três transecções dentro de floresta) foram amostrados. Os ambientes foram caracterizados quanto ao tipo de vegetação presente, ao tipo de corpo d'água quando presente e à densidade da vegetação, obtida através de estimativa visual no local, sendo considerada abundante quando cobria $50 \%$ ou mais do ambiente, e esparsa quando cobria até $49 \%$ do ambiente amostrado (Tab. I).

O inventário e a estimativa da abundância de cada espécie foram efetuados pelo método de "amostragem em sítio de reprodução" (SCOTT JR \& WoOdWARD, 1994) em corpos d'água e pelo método de busca aural em transecções para espécies que vocalizam distantes dos corpos d'água (Conte \& Rossa-Feres, 2007). O perímetro de cada açude e trechos de 120 metros de comprimento de cada córrego e transecções foi percorrido lentamente, por duas pessoas, com mesma velocidade e em todos os ambientes. Como o turno diário de vocalização dos machos difere entre as espécies, a seqüência de amostragem foi determinada por sorteio, com o intuito de aleatorizar o horário de amostragem em cada corpo d'água. A classificação taxonômica das espécies registradas seguiu Frost (2014).

Análises de dados. A estimativa de riqueza de espécies na área, considerando o levantamento efetuado nos corpos d'água e no interior de floresta, foi calculada com base na incidência mensal das espécies, por extrapolação da curva de acumulação de espécies pelo índice "Incidencebased Coverage Estimator" - ICE (ChAO \& LeE, 1992).

A influência do clima (temperatura, precipitação pluviométrica e umidade relativa do ar) sobre a variação mensal na riqueza e na abundancia de indivíduos encontrados nos ambientes amostrados, foi verificada pela aplicação de regressão linear simples (ZAR, 1999). A análise com temperatura (mínima e máxima) e umidade relativa do ar foi feita com as médias dos dados obtidos 30,15 e cinco dias antes da fase de campo, enquanto a análise com precipitação foi feita com a somatória para estes mesmos períodos.

Para avaliar a dependência da riqueza em função do tamanho das áreas amostradas, da quantidade e dos tipos de ambientes amostrados, foi realizada uma análise de matriz de correlação (ZAR, 1999) com um total de nove localidades, cuja anurofauna foi inventariada (Anexo 1).

Para determinar o tamanho das áreas amostradas a serem comparadas, elas foram localizadas e visualizadas na ferramenta Google Earth, e sobre cada uma dessas áreas foi desenhado um polígono, abrangendo os pontos mais externos de amostragem de cada inventário. Posteriormente, com a utilização do programa GE-Path v. 1.4.6 (SGRILLO, 2012), foi determinada a área total e o perímetro de cada localidade amostrada (Tab. II).

Para a determinação de tipos de ambientes amostrados em cada localidade, foram designadas sete categorias: 1) Brejo: corpo d'água lêntico ou estagnado, com uma lâmina de água acumulada sobre um fundo lodoso; 2) Açude: corpo d'água de constante troca, alimentado com água de rios e/ou córregos represada sobre um fundo

Tab. I. Caracterização dos ambientes amostrados no Parque Municipal São Luís de Tolosa, Rio Negro, Paraná, entre setembro de 2008 e agosto de 2009: AB1, açude em borda florestal 1; AB2, açude em borda florestal 2; AAA, açude em área aberta; AIF, açude no interior de floresta; PTF, poça temporária no interior de floresta; TC1, trecho em córrego 1; TC2, trecho em córrego 2; TPR, trecho paralelo a um rio; TF1, trecho dentro de floresta 1; TF2, trecho dentro de floresta 2; TF3, trecho dentro de floresta 3; Abo, arbórea; Arb, arbustiva; Her, herbácea; Pte, pteridófitas; Aqu, aquáticas. A densidade da vegetação nos ambientes foi obtida através de estimativa visual no local.

\begin{tabular}{|c|c|c|c|c|}
\hline \multirow[b]{2}{*}{ Ambiente } & \multirow[b]{2}{*}{ Tipo de vegetação } & \multirow[b]{2}{*}{ Tipo de corpo d'água } & \multicolumn{2}{|c|}{ Densidade da vegetação } \\
\hline & & & Interior & Marginal \\
\hline $\mathrm{AB} 1$ & Abo, Arb, Her, Aqu & Lêntico & Abundante & Abundante \\
\hline AB2 & Abo, Arb, Her, Aqu & Lêntico & Esparsa & Abundante \\
\hline AAA & Abo, Arb, Her, Aqu & Lêntico & Ausente & Esparsa \\
\hline AIF & Abo, Arb, Her, Aqu & Lêntico & Esparsa & Abundante \\
\hline PTF & Abo, Arb, Her, Aqu, Pte & Lêntico & Abundante & Abundante \\
\hline $\mathrm{TC} 1$ & Abo, Arb, Her, Pte & Lótico & Ausente & Abundante \\
\hline $\mathrm{TC} 2$ & Abo, Arb, Her, Pte & Lótico & Ausente & Abundante \\
\hline TPR & Abo, Arb, Her, Pte & - & - & Abundante \\
\hline TF1 & Abo, Arb, Her, Pte & - & - & Abundante \\
\hline $\mathrm{TF} 2$ & Abo, Arb, Her, Pte & - & - & Abundante \\
\hline TF3 & Abo, Arb, Her, Pte & - & - & Abundante \\
\hline
\end{tabular}


Tab. II. Variáveis de área, quantidade de ambientes e tipos de ambientes para localidades com anurofauna inventariada em Floresta Ombrófila Mista. Informações obtidas através de literatura ou comunicação pessoal, e analisadas em relação à riqueza registrada em cada localidade. PSLT - Parque Municipal São Luís de Tolosa (Presente estudo); SJDP - São José dos Pinhais (Conte \& Rossa-Feres, 2006); TSUL - Tijucas do Sul (Conte \& Machado, 2005); FZGA - Fazenda Gralha Azul (Conte \& Rossa-Feres, 2007); FCH1 - FLONA de Chapecó, área 1 (LuCAs \& Fortes, 2008); FCH2 - FLONA de Chapecó, área 2 (LuCAS \& FoRTES, 2008); GCAR - General Carneiro, STCL - parque estadual Santa Clara e PNAR - Parque Nacional das Araucárias (Carlos Eduardo Conte, com. pess.).

\begin{tabular}{|c|c|c|c|c|c|c|c|c|c|}
\hline & PSLT & SJDP & TSUL & FZGA & FCH1 & $\mathrm{FCH} 2$ & GCAR & STCL & PNAR \\
\hline Área total (ha) & 55 & 420 & 116 & 195 & 411 & 851 & 449 & 3875 & 5060 \\
\hline Quantidade de ambientes & 11 & 12 & 4 & 7 & 5 & 5 & 14 & 26 & 14 \\
\hline Riqueza & 24 & 47 & 27 & 36 & 19 & 24 & 25 & 26 & 34 \\
\hline \multicolumn{10}{|l|}{ Ambientes amostrados } \\
\hline Taboal & 0 & 1 & 0 & 1 & 0 & 0 & 0 & 0 & 0 \\
\hline Brejo (área aberta) & 0 & 1 & 0 & 0 & 0 & 0 & 1 & 0 & 0 \\
\hline Brejo (floresta) & 1 & 0 & 1 & 0 & 0 & 0 & 0 & 1 & 0 \\
\hline Brejo (borda) & 1 & 1 & 0 & 1 & 0 & 0 & 0 & 0 & 0 \\
\hline Açude/Lago (área aberta) & 1 & 1 & 1 & 1 & 1 & 1 & 1 & 1 & 1 \\
\hline Açude/Lago (borda) & 0 & 0 & 0 & 1 & 1 & 1 & 0 & 0 & 0 \\
\hline Poça temporária (área aberta) & 0 & 1 & 0 & 1 & 0 & 0 & 1 & 0 & 1 \\
\hline Poça temporária (floresta) & 1 & 1 & 1 & 1 & 0 & 0 & 0 & 1 & 1 \\
\hline Poça temporária (borda) & 0 & 0 & 0 & 0 & 0 & 0 & 1 & 0 & 1 \\
\hline Nascente & 0 & 1 & 0 & 1 & 0 & 0 & 1 & 1 & 1 \\
\hline Rio & 1 & 1 & 0 & 0 & 0 & 0 & 1 & 1 & 1 \\
\hline Riacho & 1 & 1 & 0 & 0 & 1 & 1 & 0 & 1 & 0 \\
\hline Trecho (floresta) & 0 & 1 & 1 & 1 & 1 & 1 & 1 & 1 & 1 \\
\hline Tipos de ambientes & 6 & 10 & 4 & 8 & 4 & 4 & 7 & 7 & 7 \\
\hline
\end{tabular}

lodoso ou rochoso; 3) Poça temporária: corpo d'água estagnado, com água acumulada da chuva; 4) Rio: corpo d'água lótico com mais de $1,5 \mathrm{~m}$ de largura; 5) Riacho: corpo d'água lótico com menos de $1,5 \mathrm{~m}$ de largura; 6 ) Nascente: corpo d'água raso de constante troca proveniente de uma nascente; e 7) Trecho de floresta: trecho no interior de floresta delimitado arbitrariamente para o registro de espécies que vocalizam e se reproduzem distante de corpo d'água, como por exemplo, espécies com desenvolvimento direto e/ou bromelícolas (sensu HADDAD et al., 2008). Também foi considerado se os ambientes estavam inseridos em área aberta, em borda ou interior de floresta.

Os dados para localização, quantificação e caracterização dos ambientes foram obtidos na literatura disponível para cada área ou diretamente com os autores de cada trabalho, quando o mesmo não continha todas as informações necessárias para a análise (Tab. II). O material coletado foi tombado e depositado na Coleção Científica do Departamento de Zoologia e Botânica de São José do Rio Preto (DZSJRP -Anexo 1).

\section{RESULTADOS}

Riqueza e composição de espécies. Foi registrada a ocorrência de 24 espécies pertencentes a 13 gêneros, distribuídos em sete famílias: Brachycephalidae (1); Bufonidae (2); Centrolenidae (1); Hylidae (13); Leptodactylidae (4); Microhylidae (1) e Odontophrynidae (2) (Tab. III). A curva de acumulação de espécies tende a uma assíntota a partir da décima primeira coleta e a anurofauna registrada corresponde a $96 \%$ da riqueza estimada (ICE $\approx 25$ espécies) para o conjunto de ambientes amostrados (Fig. 2). O número de ambientes utilizados por cada espécie variou de um a dez, enquanto que o número de espécies ocupando um mesmo ambiente variou de um a 17. Os ambientes com maior número de espécies foram PTF $(n=17), \operatorname{AB} 1(n=11)$ e AB2 $(n=7)$. Já na trecho de floresta TF3 foi registrado o menor número de espécies $(\mathrm{n}=1)$ (Tab. III).

Quanto ao uso de habitat, dez espécies (43\%) ocuparam somente habitats ambientes florestais, três (13\%) ocuparam somente a borda da floresta e nenhuma ocupou somente a área aberta. Quatro espécies (17\%) ocuparam tanto ambientes florestais quanto de borda, uma (5\%) ocupou um ambiente de borda e área aberta, e cinco (22\%) ocorreram tanto em área aberta quanto em borda e interior de floresta (Tab. III).

Nas diferentes taxocenoses de anuros de FOM, houve um maior registro de espécies em inventários que abrangeram mais tipos de ambientes $\left(p=0,004 ; r^{2}=0,840\right)$.

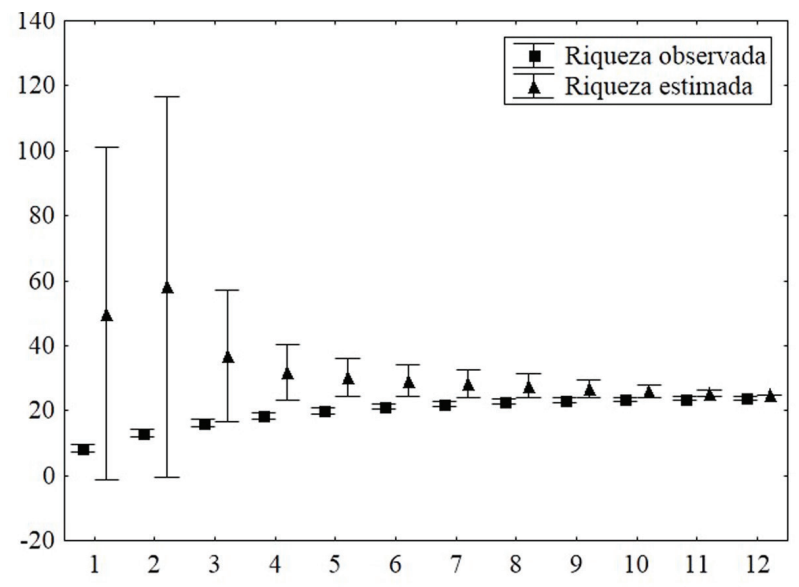

Fig. 2. Riqueza observada e estimada (ICE) para o esforço amostral de 12 fases de campo realizadas no Parque Municipal São Luís de Tolosa, Rio Negro, PR, entre setembro de 2008 e agosto de 2009. 
Tab. III. Anfíbios anuros registrados em 11 ambientes no Parque Municipal São Luís de Tolosa, Rio Negro, Paraná, entre setembro de 2008 e agosto de 2009. (AAA, açude em área aberta; AB1, açude em borda florestal 1; AB2, açude em borda florestal 2; AIF, açude no interior de floresta; TPR, transecção paralela a um rio; TC1, transecção em córrego 1; TC2, transecção em córrego 2; TF1, transecção dentro de floresta 1; TF2, transecção dentro de floresta 2; TF3, transecção dentro de floresta 3; PTF, poça temporária no interior de floresta; F.O., frequência de ocorrência de cada espécie em relação ao número total de ambientes amostrados; FLO, floresta; BOR, borda da floresta; FEB, floresta e borda da floresta; BAA, borda da floresta e área aberta; THD, todos os habitat disponíveis). (*) Referente ao ambiente não avaliado quantativamente, sendo considerado apenas a presença (1) ou ausência (0) de cada espécie.

\begin{tabular}{|c|c|c|c|c|c|c|c|c|c|c|c|c|c|c|}
\hline Taxa & $\mathrm{AB} 1$ & AB2 & AAA & AIF & TPR & $\mathrm{TC} 1$ & $\mathrm{TC} 2$ & TF1 & TF2 & TF3 & $\mathrm{PTF}^{*}$ & Total & F.O. & $\begin{array}{l}\text { Uso de } \\
\text { habitat }\end{array}$ \\
\hline \multicolumn{15}{|l|}{ BRACHYCEPHALIDAE } \\
\hline Ischnocnema guentheri (Steindachner, 1864) & 0 & 0 & 0 & 0 & 22 & 0 & 2 & 21 & 9 & 0 & 0 & 54 & $36 \%$ & FLO \\
\hline \multicolumn{15}{|l|}{ BUFONIDAE } \\
\hline Rhinella abei (Baldissera, Camaraschi \& Haddad, 2004) & 3 & 1 & 3 & 0 & 0 & 0 & 0 & 0 & 0 & 0 & 1 & 7 & $36 \%$ & THD \\
\hline R. icterica (Spix, 1824) & 0 & 2 & 4 & 1 & 0 & 1 & 0 & 0 & 0 & 0 & 1 & 8 & $45 \%$ & THD \\
\hline \multicolumn{15}{|l|}{ CENTROLENIDAE } \\
\hline Vitreorana uranoscopa (Müller, 1924) & 0 & 0 & 0 & 0 & 12 & 0 & 5 & 0 & 13 & 0 & 0 & 30 & $27 \%$ & FLO \\
\hline \multicolumn{15}{|l|}{ HYLIDAE } \\
\hline Aplastodiscus perviridis Lutz in B. Lutz, 1950 & 18 & 2 & 0 & 1 & 1 & 5 & 0 & 0 & 0 & 0 & 0 & 27 & $45 \%$ & FEB \\
\hline Dendropsophus microps (Peters, 1872) & 6 & 0 & 0 & 0 & 0 & 0 & 0 & 0 & 0 & 0 & 1 & 6 & $18 \%$ & FEB \\
\hline D. minutus (Peters, 1872) & 21 & 3 & 4 & 0 & 0 & 0 & 0 & 0 & 0 & 0 & 1 & 28 & $36 \%$ & THD \\
\hline Hypsiboas bischoffi (Boulenger, 1887) & 82 & 69 & 41 & 29 & 1 & 4 & 2 & 1 & 1 & 0 & 1 & 230 & $90 \%$ & THD \\
\hline H. faber (Wied-Neuwied, 1821) & 8 & 2 & 1 & 0 & 0 & 0 & 0 & 0 & 0 & 0 & 0 & 11 & $27 \%$ & BAA \\
\hline H. prasinus (Burmeister, 1856) & 0 & 0 & 0 & 0 & 0 & 0 & 0 & 0 & 0 & 0 & 1 & 0 & $9 \%$ & FEB \\
\hline Scinax imbegue Nunes, Kwet \& Pombal Jr, 2012 & 8 & 0 & 0 & 0 & 0 & 0 & 0 & 0 & 0 & 0 & 0 & 8 & $9 \%$ & BOR \\
\hline S. aromothyella Faivovich, 2005 & 0 & 0 & 0 & 0 & 0 & 0 & 0 & 0 & 0 & 0 & 1 & 0 & $9 \%$ & FEB \\
\hline S. fuscovarius (Lutz, 1925) & 0 & 0 & 0 & 0 & 0 & 0 & 0 & 0 & 0 & 0 & 1 & 0 & $9 \%$ & FEB \\
\hline S. perereca Pombal Jr, Haddad \& Kasahara, 1995 & 14 & 9 & 2 & 1 & 0 & 0 & 1 & 0 & 0 & 0 & 1 & 27 & $55 \%$ & THD \\
\hline S. rizibilis (Bokermann, 1964) & 0 & 0 & 0 & 0 & 0 & 2 & 0 & 0 & 0 & 0 & 1 & 2 & $18 \%$ & FEB \\
\hline S. sp. (gr. catharinae) & 1 & 0 & 0 & 19 & 0 & 7 & 3 & 0 & 0 & 0 & 0 & 30 & $36 \%$ & FEB \\
\hline Trachycephalus dibernardoi Kwet \& Solé, 2008 & 0 & 0 & 0 & 0 & 0 & 0 & 0 & 0 & 0 & 0 & 1 & 0 & $9 \%$ & FEB \\
\hline \multicolumn{15}{|l|}{ LEPTODACTYLIDAE } \\
\hline Adenomera nana Müller, 1922 & 0 & 0 & 0 & 0 & 0 & 0 & 0 & 13 & 4 & 3 & 1 & 20 & $36 \%$ & FEB \\
\hline Leptodactylus notoaktites Heyer, 1978 & 0 & 0 & 0 & 0 & 0 & 0 & 0 & 0 & 0 & 0 & 1 & 0 & $9 \%$ & FEB \\
\hline L. latrans (Steffen, 1815) & 5 & 1 & 0 & 0 & 0 & 0 & 0 & 0 & 0 & 0 & 1 & 6 & $27 \%$ & FEB \\
\hline Physalaemus cuvieri Fitzinger, 1826 & 8 & 1 & 0 & 0 & 0 & 0 & 0 & 0 & 0 & 0 & 1 & 9 & $27 \%$ & BOR \\
\hline \multicolumn{15}{|l|}{ MICROHYLIDAE } \\
\hline Chiasmocleis leucosticta (Boulenger,1888) & 0 & 0 & 0 & 0 & 0 & 0 & 0 & 0 & 0 & 0 & 1 & 0 & $9 \%$ & FEB \\
\hline \multicolumn{15}{|l|}{ ODONTOPHRYNIDAE } \\
\hline Odontophrynus americanus (Duméril \& Bibron, 1841) & 0 & 0 & 0 & 0 & 3 & 0 & 0 & 0 & 0 & 0 & 0 & 0 & $9 \%$ & BOR \\
\hline Proceratophrys brauni Kwet \& Faivovich, 2001 & 24 & 0 & 0 & 4 & 4 & 19 & 0 & 24 & 0 & 0 & 1 & 75 & $55 \%$ & FEB \\
\hline Abundância total & 198 & 90 & 55 & 55 & 43 & 38 & 13 & 59 & 27 & 3 & - & 581 & & \\
\hline Riqueza total & 12 & 9 & 6 & 6 & 6 & 6 & 5 & 4 & 4 & 1 & 17 & 24 & & \\
\hline
\end{tabular}

O mesmo não ocorreu para tamanho da área amostrada ( $\mathrm{p}$ $\left.=0,828 ; \mathrm{r}^{2}=0,084\right)$ e quantidade de ambientes amostrados $\left(p=0,371 ; r^{2}=0,339\right)$ (Tab. IV).

Distribuição temporal. Todas as 24 espécies foram encontradas em atividade de vocalização predominantemente noturna, com exceção de Adenomera nana, observada em atividade de vocalização durante o crepúsculo vespertino (Fig. 3). Machos de Proceratophrys brauni foram observados vocalizando durante a tarde nos meses de fevereiro e julho. A única espécie em que os machos foram observados em atividade de vocalização em todos os meses foi Hypsiboas bischoffi, sendo que no mês de abril foi a única espécie encontrada vocalizando (Fig. 3).

Os maiores registros de riqueza e abundância ocorreram durante o período com maior volume de chuva, entre outubro de 2008 e janeiro de 2009 (Tab. V; Fig. 3).

Com relação ao período de vocalização das espécies, foi possível separá-las em: 1) anuais, que vocalizaram quase o ano todo [D. minutus, H. bischoffi, Scinax sp. (gr. catharinae) e P. brauni]; 2) de estação chuvosa, que vocalizaram somente no período mais quente e chuvoso entre setembro e fevereiro (A. perviridis, $V$. uranoscopa, $H$. faber, H. prasinus, Ischnocnema guentheri, A. nana, L. notoaktites, $P$. cuvieri, Scinax imbegue, S. aromothyella, S. fuscovarius); 3) de início de estação chuvosa, que vocalizaram somente após um grande volume de chuva desta estação (O. americanus e T. dibernardoi); 4) esporádicas, que vocalizaram após chuvas fortes ao longo do ano todo (R. abei, $R$. icterica, D. microps, L. latrans, S. rizibilis, $S$. perereca e C. leucosticta) (Fig. 3). 

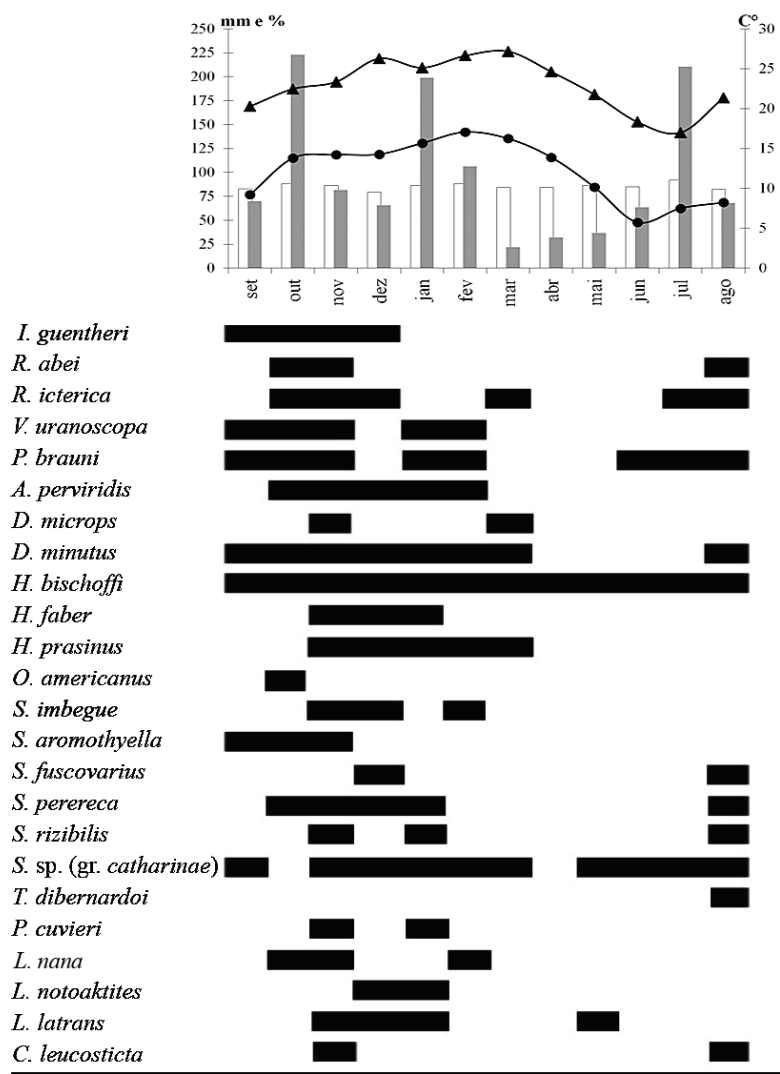

Fig. 3. Valores para temperatura máxima $(\boldsymbol{\Delta})$, temperatura mínima $(\bullet)$, umidade média (colunas brancas), precipitação total (colunas pretas) e período de vocalização das espécies registradas no Parque Municipal São Luís de Tolosa, Rio Negro, PR entre setembro de 2008 e agosto de 2009. Valores de precipitação total em milímetros $(\mathrm{mm})$, de umidade média em porcentagem (\%) e de temperatura em graus Celsius $\left({ }^{\circ} \mathrm{C}\right)$.

\section{DISCUSSÃO}

Riqueza e composição de espécies. As 24 espécies registradas correspondem aproximadamente $20 \%$ da anurofauna conhecida para a FOM ( $=129$; CARLOS Eduardo Conte, observ. pess. ). A riqueza total representou $96 \%$ da riqueza estimada, indicando que o esforço de amostragem foi satisfatório. Além disso, em comparação com outros estudos realizados em áreas inseridas na FOM, a riqueza encontrada foi similar à registrada em Tijucas do Sul ( $\mathrm{n}=23$; CONTE \& MACHADO, 2005) e Floresta Nacional de Irati ( $\mathrm{n}=23$; CARlos Eduardo Conte, observ. pess.). Porém a riqueza registrada foi menor do que a registrada em São José dos Pinhais $(\mathrm{n}=34$; Conte $\&$ Rossa-Feres, 2006), Fazenda Rio Grande ( $\mathrm{n}=32$; Conte $\&$ Rossa-Feres, 2007), Parque Nacional das Araucárias ( $n=34$; CARLos Eduardo Conte, observ. pess.) e Floresta Nacional de Chapecó ( $\mathrm{n}=28$; LuCAS \& Fortes, 2008).

Através do trabalho de identificação, uma espécie (representando $4 \%$ do total) encontrada no PSLT foi categorizada como não descrita formalmente. Ela é uma Scinax WAGLER 1830, pertencente ao grupo catharinae, taxonomicamente próxima de Scinax catharinae (Boulenger, 1888). O gênero Scinax abriga centenas de espécies (Frost, 2012) e muitas delas pertences a complexos de difícil identificação devido às suas similaridades morfológicas (Pombal JR et al., 1995; Nunes et al., 2012), resultando em incertezas taxonômicas e revisões frequentes (e. g. Pombal JR et al., 1995; Faivovich, 2002; Faivovich et al., 2005; Nunes et al., 2012). Uma das espécies registradas no PSLT é parte de um complexo de espécies de Scinax que foi revisado taxonomicamente recentemente por NUNES et al. 2012. De acordo com esse trabalho, a espécie ocorrente na região do PSLT é Scinax tymbamirim Nunes, Kwet \& Pombal Jr, 2012. Entretanto, através de uma revisão do canto, constata-se que a ocorrência é de Scinax imbegue para o PSLT e não de Scinax tymbamirim (Anexos 2 e 3).

Vários estudos têm demonstrado a importância da heterogeneidade ambiental para a diversidade de anfíbios anuros (PARRIS, 2004; Vasconcelos et al., 2009; Keller et al., 2009; Silva et al., 2012, Pacheco \& Vasconcelos, 2012), em especial para taxocenoses da região Neotropical, que possuem uma elevada diversificação de modos reprodutivos (HAdDAd \& PRAdo, 2005). Neste sentido, amostragens em regiões com maior variedade de ambientes utilizados para a reprodução (e.g. poças temporárias, brejos, riachos) são mais propensos a abrigar uma riqueza elevada e espécies por satisfazer os requisitos necessários a reprodução de um maior número de espécies (ZIMMERMAN \& Simberloff, 1996; Haddad \& Prado, 2005). Este fato fica evidenciado nos dados obtidos em estudos com anfíbios de FOM: áreas de grande extensão, mas com menos tipos de ambientes, apresentaram menor riqueza de espécies quando comparados com áreas de menor extensão, mas com maior quantidade de tipos de ambientes, que apresentaram maior riqueza de espécies.

Não obstante, a área total do fragmento ou do ambiente onde ocorrem as espécies é um fator importante a ser considerado, uma vez que, em teoria, a diminuição da área tende a levar à diminuição da riqueza local, da abundância e ao aumento do risco de extinção (CONNOR \& McCoy, 1979; Shaffer, 1981, Bell \& Donnelly, 2006). Correlações positivas entre diversidade e área já foram encontradas para diversos grupos animais como aves (Hamilton \& Armstrong, 1965), insetos (Nilsson, 1988) e peixes (Schlosser, 1995). Entretanto, caso de taxocenoses de anfíbios analisadas, essa correlação não foi encontrada. Provavelmente porque anuros possuem características peculiares como a capacidade limitada de locomoção e dispersão associados a especificidade de modo reprodutivo para muitas espécies (Wells, 2007). Esse é o caso de algumas espécies ocorrentes no PSLT, que ocuparam microhabitat específico durante eventos reprodutivos, como Vitreorana uranoscopa (vegetação na margem de riachos e corredeiras), Ischnocnema guentheri (chão úmido da floresta) e Proceratophrys brauni (leito rochoso ou lamacento de riachos ou poças). Isso pode, portanto, diminuir a influência do tamanho do fragmento em torno dos ambientes de reprodução e refúgio onde estão inseridos, e aumentando a importância da variedade de ambientes disponíveis. 
Tab. IV. Matriz de correlação entre riqueza de espécies e as variáveis identificadas para diferentes localidades com anurofauna inventariada na Floresta Ombrófila Mista, com valores de ' $\mathrm{p}$ ' e ' $\mathrm{r}^{2}$ ' (em negrito, valores significativos).

\begin{tabular}{|c|c|c|c|c|c|}
\hline & Riqueza & Área & Perímetro & Quantidade de ambientes & Tipos de ambientes \\
\hline Riqueza & & 0,828 & 0,728 & 0,371 & 0,004 \\
\hline Área & 0,084 & & 0,000 & 0,227 & 0,680 \\
\hline Perímetro & 0,135 & 0,993 & & 0,191 & 0,592 \\
\hline $\mathrm{N}^{\mathrm{o}}$ de habitats & 0,339 & 0,446 & 0,479 & & 0,047 \\
\hline $\mathrm{N}^{\mathrm{o}}$ de categorias & 0,840 & 0,160 & 0,207 & 0,671 & \\
\hline
\end{tabular}

Tab. V. Valores de 'p' e ' $\mathrm{r}^{2}$ ajustado (aj.)' resultantes das análises de regressão linear simples, para a riqueza e a abundância em função de cada variável climática, referentes aos dados obtidos no Parque Municipal São Luís de Tolosa, Rio Negro, Paraná, entre setembro de 2008 e agosto de 2009. Em negrito, valores considerados significativos.

\begin{tabular}{|c|c|c|}
\hline Abundância de indivíduos x variáveis climáticas & $\mathrm{p}$ & $\mathrm{r}^{2}$ aj. \\
\hline Temperatura máxima com média de 30 dias anteriores a fase & 0,830 & $-0,095$ \\
\hline Temperatura máxima com média de 15 dias anteriores a fase & 0,533 & $-0,056$ \\
\hline Temperatura máxima com média de 5 dias anteriores a fase & 0,932 & $-0,099$ \\
\hline Temperatura mínima com média de 30 dias anteriores a fase & 0,286 & 0,024 \\
\hline Temperatura mínima com média de 15 dias anteriores a fase & 0,160 & 0,106 \\
\hline Temperatura mínima com média de 5 dias anteriores a fase & 0,451 & $-0,036$ \\
\hline Precipitação acumulada 30 dias anteriores a fase & $\mathbf{0 , 0 0 7}$ & 0,487 \\
\hline Precipitação acumulada 15 dias anteriores a fase & 0,019 & $\mathbf{0 , 3 8 3}$ \\
\hline Precipitação acumulada 5 dias anteriores a fase & $\mathbf{0 , 0 3 8}$ & $\mathbf{0 , 3 0 1}$ \\
\hline Umidade com média de 30 dias anteriores a fase & 0,144 & 0,121 \\
\hline Umidade com média de 15 dias anteriores a fase & 0,307 & 0,014 \\
\hline Umidade com média de 5 dias anteriores a fase & 0,868 & $-0,097$ \\
\hline Riqueza de espécies x variáveis climáticas & $\mathrm{p}$ & $\mathrm{r}^{2} \mathrm{aj}$ \\
\hline Temperatura máxima com média de 30 dias anteriores a fase & 0,543 & $-0,058$ \\
\hline Temperatura máxima com média de 15 dias anteriores a fase & 0,275 & 0,030 \\
\hline Temperatura máxima com média de 5 dias anteriores a fase & 0,510 & $-0,051$ \\
\hline Temperatura mínima com média de 30 dias anteriores a fase & 0,209 & 0,068 \\
\hline Temperatura mínima com média de 15 dias anteriores a fase & 0,110 & 0,158 \\
\hline Temperatura mínima com média de 5 dias anteriores a fase & 0,233 & 0,053 \\
\hline Precipitação acumulada 30 dias anteriores a fase & $\mathbf{0 , 0 2 8}$ & $\mathbf{0 , 3 3 7}$ \\
\hline Precipitação acumulada 15 dias anteriores a fase & 0,174 & 0,094 \\
\hline Precipitação acumulada 5 dias anteriores a fase & 0,164 & 0,103 \\
\hline Umidade com média de 30 dias anteriores a fase & 0,368 & $-0,010$ \\
\hline Umidade com média de 15 dias anteriores a fase & 0,902 & $-0,098$ \\
\hline Umidade com média de 5 dias anteriores a fase & 0,524 & $-0,054$ \\
\hline
\end{tabular}

Quanto à ocupação e uso de habitat, a ocorrência em floresta, em borda ou em área aberta pode ser um reflexo das características generalistas ou específicas de cada espécie (WeLls, 2007). No presente estudo, algumas espécies foram classificadas como generalistas, ocorrendo em ambientes tanto de área aberta quanto florestal. Esse é um padrão que tem sido registrado em estudos realizados nos domínios da Mata Atlântica (lattu sensu), incluindo áreas de FOM (e.g. HADDAD \& SAZIMA, 1992; Machado et al., 1999; ConTe \& Rossa-Feres, 2006, 2007). Algumas espécies ocorrentes nesse estudo, como Rhinella abei e Dendropsophus microps, são frequentemente registradas ocupando ou se deslocando pelo interior da floresta (CONTE \& Rossa-Feres, 2006, 2007). Porém, podem se reproduzir também na borda e na área aberta, possivelmente porque a localização dos ambientes de reprodução e o gradiente de fragmentação podem levar espécies de anfíbios que ocupam a floresta a se deslocarem por áreas abertas (PIANKA, 1994; GibBs, 1998; BECKER et al., 2007; BEGON et al, 2007). O fato de nenhuma espécie registrada ter ocupado somente a área aberta indica que todas as espécies dependem do fragmento florestal em algum nível. Esse foi um resultado esperado, pois mesmo espécies que são exclusivas de área aberta utilizam fragmentos florestais fora do período reprodutivo (SILVA \& RosSa-Feres, 2007), caso da espécie Odontophrynus americanus, que é normalmente registrada em atividade de reprodução em áreas abertas, mas está associada a fragmentos florestais (LUCAS \& ForTES, 2008, Carlos Eduardo Conte, observ. pess.).

Distribuição temporal. No presente estudo, a precipitação foi determinante para o aumento da riqueza e da abundância, resultado comumente encontrado em outras taxocenoses, pois a reprodução dos anfíbios é fortemente influenciada por fatores climáticos (Duellman \& TRUeB, 1986), padrão que tem sido observado em outros estudos no sul e sudeste do Brasil (e.g. Bertoluci, 1998; Bernarde \& KoKubum, 1999; Toledo et al., 2003; VAsConcelos \& Rossa-Feres, 2005; Prado et al., 2005; Conte \& RossaFERES, 2006, 2007). Apesar disso, a temperatura e a umidade não favoreceram o aumento da riqueza e abundância da taxocenose do PSLT. Provavelmente pelo fato do número de espécies e indivíduos em atividade reprodutiva ter diminuído quando as médias de temperatura se mantiveram altas em 
março e abril de 2009 , e ter aumentado quando as médias de temperatura caíram em maio, junho e julho de 2009. Não obstante, deve-se levar em consideração que o clima não atua como um processo isolado, mas sim em conjunto com outros processos como a predação, a competição ou a modificação física e química do ambiente, influenciando a distribuição temporal das espécies (MARSH, 2001; Wells, 2007). Estudos onde a temperatura e a precipitação não influenciaram a diversidade da anurofauna mostraram que fatores normalmente não analisados, como fotoperíodo (Вотн et al., 2008), ou tamanho e profundidade dos corpos d'água durante o ano (BАBВIT, 2005), também podem influenciar o período reprodutivo das espécies.

$\mathrm{O}$ grande volume de chuvas entre setembro de 2008 e janeiro de 2009 preencheu a PTF, que foi o ambiente com a maior riqueza, abrigando $66 \%$ do total de espécies do fragmento, resultado similar ao encontrado por Conte \& Rossa-Feres (2007), que registraram 56\% da riqueza total de um estudo em Fazenda Rio Grande em uma poça temporária de área aberta associada a um fragmento de FOM. Apesar desse ambiente não ter sido analisado quantitativamente no PSLT, o número de machos de algumas espécies vocalizando nele durante a estação chuvosa foi perceptivelmente maior em comparação com os outros ambientes, especialmente para Dendropsophus microps e Scinax rizibilis. Essa variação pode reforçar a preferência de tais espécies para reprodução em poças temporárias, com agregações de grande densidade por períodos prolongados, como visto em BASTOS \& HADDAD (1999) E Pombal JR \& HADDAD (2005). A riqueza mais alta do ambiente PTF pode ser atribuída pelo fato da inexistência de peixes que são predadores de girinos e podem ter uma forte influência negativa sobre a taxocenose, independentemente da espécie de peixe ocorrente ser nativa (Wellborn et al., 1996; Hecnar \& M'Closkey, 1997) ou introduzida (PILlod et al. 2010). Outra possibilidade é que a heterogeneidade ambiental seja um fator importante, já que o ambiente PTF era visivelmente o mais heterogêneo, fornecendo assim uma maior variedade de microhabitat que foram utilizados por diferentes espécies, aumentando a riqueza local (VASCONCELOS et al., 2009).

De acordo com o período de vocalização, $50 \%$ das espécies foram categorizadas como sendo de estação chuvosa e $20 \%$ como anuais, sendo essas proporções concordantes com as observadas nas áreas próximas (CONTE \& Machado, 2005; Conte \& Rossa-Feres, 2006, 2007). Esse resultado é esperado, devido ao clima predominante em quase toda a extensão da FOM, que apresenta chuvas concentradas nos meses mais quentes e com ocorrência frequente de geadas no inverno (LeITE, 1990). Sendo assim, taxocenoses que estejam sob as mesmas condições de clima provavelmente terão padrões similares, mas pode haver pequenas variações devido à heterogeneidade de microclimas em cada fragmento, ocasionado pelas diferenças de cobertura vegetal, estrutura da matriz e tamanho (RAmos \& SAntos, 2006).
Apesar das espécies terem sido categorizadas de acordo com sua ocorrência e período de vocalização, essas definições podem não ser as mesmas para diferentes locais ou mesmo para diferentes períodos em que os locais foram amostrados. No presente estudo, a espécie Physalaemus cuvieri foi categorizada como rara, enquanto em Tijucas do Sul (Conte \& Machado, 2005), que dista apenas 80 $\mathrm{km}$ do PSLT, ela foi registrada como comum; tal qual é o registro em outras localidades (BERNARDE \& MACHADO, 2001; Conte \& Rossa-Feres, 2007; Santos et al., 2008). Isso também é demonstrado por ABRUNHosA et al. (2006), por exemplo, que classificaram Physalaemus signifer como oportunista, comparando em seguida com os registros de Wogel et al. (2002), no qual a espécie apresentou longos períodos reprodutivos. Esses resultados inconsistentes podem ser reflexos da plasticidade que algumas espécies de anuros possuem na ocupação e distribuição de habitat, possuindo um caráter estenóico ou eurióico de acordo com a paisagem e estrutura de onde estão inseridos (DuelLman, 1999; Wells, 2007).

Conservação. O fragmento do PSLT apresenta tamanho reduzido e alterações antrópicas (RIo NEGRO, 2004), mas cerca de $40 \%$ das espécies registradas dependem diretamente de ambientes florestais e uma espécie nova foi registrada. Isso ilustra o potencial de diversidade que outros fragmentos ainda não amostrados podem ter, e também reforça a necessidade de conservação de remanescentes inseridos na FOM (CONTE \& Rossa-Feres, 2007). Além disso, espécies como Vitreorana uranoscopa, Adenomera nana e Ischnocnema guentheri, demonstram que o fragmento satisfaz os requisitos para reprodução e manutenção dessas espécies, consideradas exigentes. No caso da espécie $V$. uranoscopa, os machos ocupam as margens de rios e córregos durante o período reprodutivo, e os girinos desenvolvem-se no fundo do corpo d'água sob a vegetação em decomposição (HEYER, 1985; MACHADO et al., 2010). Adenomara nana é uma espécie que foi recentemente revalidada (KWET, 2007) e que ocupa estritamente o interior da floresta, vocalizando sobre a serrapilheira, e possui distribuição limitada no Paraná e em Santa Catarina (CONTE et al., 2010). Ischnocnema guentheri possui um modo reprodutivo especializado e depende de ambientes florestais (HADDAD \& Prado, 2005), o que aumenta a preocupação acerca de sua manutenção.

O alto nível de degradação da FOM, e a falta de medidas para conservação, preservação e recuperação de áreas florestadas, pode colocar as espécies da região em um cenário de taxocenoses isoladas, impossibilitando o estabelecimento de uma metapopulação ampla e de fluxo contínuo, especialmente para espécies que dependem de ambientes aquáticos e precisam se deslocar para garantir a reprodução e desenvolvimento de girinos (BECKER et al., 2009). Existem exceções, como indivíduos com capacidade de atravessar matrizes inóspitas entre os fragmentos e espécies sem reprodução envolvendo ambientes aquáticos, de desenvolvimento direto (BeCKer et al. 2009). Como 
agravante, a falta de estudos na FOM e na região debilita a tomada de decisões conservacionistas, devido à falta de conhecimento da história natural das espécies e da dinâmica nos fragmentos e entre eles (CONTE \& RossA-Feres, 2007). Medidas como a recuperação das áreas degradadas, da mata ciliar, de reservas de APP e o estabelecimento de corredores ecológicos devem ser consideradas essenciais para auxiliar na manutenção das espécies e evitar as consequências da fragmentação.

Agradecimentos. À bióloga Lenita Kozak (Prefeitura de Rio Negro), pelo apoio logístico. Ao Prof. Dr. Júlio César de Moura-Leite e ao M. Sc. Janael Ricetti, pelas contribuições ao artigo. A um dos revisores anônimos pela excelente e criteriosa revisão do manuscrito. Aos biólogos Leonardo Tedeschi, Ernani A. O. Mossanek, Jéssica F. Antunes e Hamanda B. Cavalheri, e à Fernanda A. dos Santos pela colaboração e companhia em algumas fases de campo. À Coordenadoria de Aperfeiçoamento de Pessoal de Nível Superior - CAPES pelas bolsas concedidas a E.J.S (Mestrado) e C.E.C. (PRODOC n ${ }^{\circ} 18$ - 32/2010). Ao Dr. Axel Kwet por ceder trechos de cantos gravados de Scinax tymbamirim e $S$. imbegue.

\section{REFERÊNCIAS BIBLIOGRÁFICAS}

Abrunhosa, P. A.; Wogel, H. \& Pombal JR, J. P. 2006. Anuran temporal occupancy in a temporary pond from the Atlantic Rainforest, Southeastern Brazil. Herpetological Journal 16:115-122.

Afonso, L. G. \& Eтerovick, P. 2007. Microhabitat choice and differential use by anurans in forest streams in southeastern Brazil. Journal of Natural History 41(13-16):937-948.

Azevedo-Ramos, C. \& Galatti, U. 2002. Patterns of amphibian diversity in Brazilian Amazonia: conservation implications. Biological Conservation 103:103-111.

Baввіт, K. J. 2005. The relative importance of wetland size and hydroperiod for amphibians in southern New Hampshire, USA. Wetlands Ecology and Management 13:269-279.

Bastos, R. P. \& HADDAD, C. F. B. 1999. Atividade reprodutiva de Scinax rizibilis (Bokermann) (Anura, Hylidae) na Floresta Atlântica, sudeste do Brasil. Revista Brasileira de Zoologia 16(2):409-421.

Becker, C. G.; Fonseca, C. R.; Haddad, C. F. B. \& Prado, P. I. 2009. Habitat Split As A Cause Of Local Population Declines OfAmphibians With Aquatic Larvae. Conservation Biology 24(1):287-294.

Beebee, T. J. C. \& Griffiths, R. A. 2005. The amphibian decline crisis: A watershed for conservation biology? Biological Conservation 125:271-285.

Begon, M.; Townsend, C. R. \& Harper, J. L. 2007. Ecologia: De indivíduos a ecossistemas. Porto Alegre, Artmed. 752p.

Bell, K. E. \& Donnelly, M. A. 2006. Influence of Forest Fragmentation on Community Structure of Frogs and Lizards in Northeastern Costa Rica. Conservation Biology 20(6):1750-1760.

Bernarde, P. S. \& Kokubum, M. N. C. 1999. Anurofauna do município de Guararapes, Estado de São Paulo, Brasil (Amphibia, Anura). Acta Biologica Leopoldensia 21:89-97.

Bernarde, P. S. \& Machado, R. A. 2001 (2000). Riqueza de espécies, ambientes de reprodução e temporada de vocalização da anurofauna em Três Barras do Paraná, Brasil (Amphibia: Anura). Cuadernos de Herpetologia 14(2):93-104.

Bertoluci, J. 1998. Annuals patterns of breeding activity in Atlantic Rainforest anurans. Journal of Herpetology 32(4):607-611.

Bertoluci, J.; Brassaloti, R. A.; Junior, J. W. R.; Vilela, V. M. F. N. \& SAWAKUCHI, W. O. 2007. Species composition and similarities among anuran assemblages of forest sites in southeastern Brazil. Scientia Agricola 64(4):364-374.

Blaustein, A. R. \& Kiesecker, J. M. 2002. Complexity in conservation: lessons from the global decline of amphibian populations. Ecology Letters 5:597-608.

Both, C.; Kaefer, I. L.; SAntos, T. G. \& Ceehin, S. T. Z. 2008. An austral anuran assemblage in the Neotropics: seasonal occurrence correlated with photoperiod. Journal of Natural History 42(3):205-222.
Castella, P. R. \& Britez, R. M. 2004. A Floresta com Araucária no Paraná: Conservação e diagnósticos dos remanescentes florestais. Brasília, Ministério do Meio Ambiente. 233p.

Chao, A. \& Lee, S. M. 1992. Estimating the number of classes via sample coverage. Journal of the American Statistical Association 87:210-217.

Chesson, P. 2000. Mechanisms of maintenance of species diversity. Annual Review of Ecological Systems 31:343-366.

Connor, E. E. \& McCoy, E. D. 1979. The statistics and biology of the species-area relationship. The American Naturalist 113:791-833.

Conte, C. E. \& Machado, R. A. 2005. Riqueza de espécies e distribuição espacial e temporal em comunidade de anuros (Amphibia, Anura) em uma localidade de Tijucas do Sul, Paraná, Brasil. Revista Brasileira de Zoologia 22(4):940-948.

Conte, C. E.; Nomura, F.; Machado, R. A.; Kwet, A.; Lingnau, R. \& Rossa-Feres, D. C. A. 2010. Novos registros na distribuição geográfica de anuros na Floresta com Araucária e considerações sobre suas vocalizações. Biota Neotropica 10(2).

Conte, C. E. \& Rossa-Feres, D. C. 2006. Diversidade e ocorrência temporal da anurofauna (Amphibia, Anura) em São José dos Pinhais, Paraná, Brasil. Revista Brasileira de Zoologia 23(1):162-175.

2007. Riqueza e distribuição espaço-temporal de anuros em um remanescente de Floresta de Araucária no sudeste do Paraná. Revista Brasileira de Zoologia 24(4):1025-1037.

Cunha, A. K.; Oliveira, I. S. \& Hartmann, M. T. 2010. Anurofauna da Colônia Castelhanos, na Área de Proteção Ambiental de Guaratuba, Serra do Mar paranaense, Brasil. Biotemas 23(2).

Duellman, W. E. 1988. Patterns of species diversity in anuran amphibians in the American Tropics. Annals of the Missouri Botanical Garden 75:79-104.

1999. Distribution patterns of amphibians in South America. In: Duellman, W. E. ed. Patterns of distribution of amphibians: A global perspective. Maryland, The John Hopkins University Press. 633p.

Duellman, W. E. \& Trueb, L. 1986. Biology of Amphibians. Baltimore, London, McGraw-Hill Publications Corporation. 670p.

Eterovick, P. C.; Carnaval, A. C. O. Q.; Borjes-Nojosa, D. M.; Silvano, D. L.; Segalla, M. V. \& Sazima, I. 2005. Amphibian declines in Brazil: An Overview. Biotropica 37(2):166-179.

Faivovich, J. 2002. A cladistic analysis of Scinax (Anura: Hylidae). Cladistics 18:367-393.

Faivovich, J.; Haddad, C. F. B.; Garcia, P. C. A.; Frost, D. R.; Campbell, J. A. \& Wheeler, W. C. 2005. Systematic review of the frog family Hylidae, with special reference to Hylinae: phylogenetic analysis and taxonomic revision. Bulletin of the American Museum of Natural History 294:1-240.

Frost, D. R. 2012. Amphibian Species of the World: an Online Reference. Version 5.5. Disponível em: $<$ http://research.amnh. org/vz/herpetology/amphibia/>. Acesso em: 14.12.2012.

GiBBs, J. P. 1998. Distribution of woodland amphibians along a forest fragmentation gradient. Landscape Ecology 13:263-268.

Gotelli, N. J.; Anderson, M. J.; Arita, H. T.; Colwell, R. K.; Connolly, S. R.; Currie, D. J.; Dunn, R. R.; Graves, G. R.; Green, J. L.; Grytnes, J.; Jiang, Y.; Jetz, W.; Lyons, K.; McCain, C. M.; Magurran, A. E.; Rahbek, C.; Rangel, T. F. L. V. B.; Soberón, J.; Webb, C. O. \& WiLLIG, M. R. 2009. Patterns and causes of species richness: a general simulation model for macroecology. Ecology Letters 12:873-886.

Gray, M. J.; SMith, L. M. \& LeYva, R. I. 2004. Influence of agricultural landscape structure on a Southern High Plains, USA, amphibian assemblage. Landscape Ecology 19:719-729.

Haddad, C. F. B \& Prado, C. P. A. 2005. Reproductive modes in frogs and their unexpected diversity in the Atlantic Forest of Brazil. BioScience 55(3).

Haddad, C. F. B. \& SAzima, I. 1992. Anfibios Anuros da Serra do Japi. In: Morellato, L. P. C. org. História natural da Serra do Japi: Ecologia e preservação de uma área florestal no sudeste do Brasil. v.1, Campinas, UNICAMP/FAPESP. p.188-211.

Haddad, C. F. B.; Toledo, L. F. \& Prado, C. P. A. 2008. Anfíbios da Mata Atlântica. São Paulo, Editora Neotropica. 244p.

HAmilton, T. H. \& ARMSTRong, N. E. 1965. Environmental determination of insular variation in birds species abundance in the Gulf of Guinea. Nature 207:148-151. 
Hecnar, S. J. \& M'Closkey, R. T. 1997. The effects of predatory fish on amphibian species richness and distribution. Biological Conservation 79:123-131

Heyer, W. R. 1985. Taxonomic and natural history notes on frogs of the genus Centrolenella (Amphibia: Centrolenidae) from southeastern Brasil and adjacent Argentina. Papéis Avulsos de Zoologia 36:1-21.

Heyer, W. R.; Donnelly, M. A.; McDiarmid, R. W.; Hayek, L. C. \& Foster, M. S. 1994. Measuring ands monitoring biological diversity. Standard methods for Amphibians. Washington, Smithsonian Institution Press. 384p.

Heyer, W. R.; Rand, A. S.; Cruz, C. A. G.; Peixoto, O. L. \& Nelson, C. E. 1990. Frogs of Boracéia. Arquivos de Zoologia 31(4):235-410.

Houlahan, J. E.; Findlay, C. S.; Schmidt, B. R.; Meyer, A. H. \& Kuzmin, S. L. 2000. Quantitative evidence for global amphibian population declines. Nature 404:752-755.

IBGE - Instituto Brasileiro de Geografia e Estatística. 2004. Mapa de biomas e vegetação. Disponível em: $<\mathrm{http} / /$ www.ibge.gov.br/ home/presidencia/noticias/noticia_visualiza.php?id_noticia $=169>$. Acesso em: 14.12.2012.

IUCN - InTERNATIONAL UNION FOR the CONSERVATION OF NATURE. 2012. The IUCN Red List of Threatened Species. Version 2012.1. Disponível em: $<\mathrm{http}: / / \mathrm{www}$.iucnredlist.org $>$. Acesso em: 14.12.2012.

Keller, A.; RöDel, M.; Linsenmair, K. E. \& Grafe, T. U. 2009. The importance of environmental heterogeneity for species diversity and assemblage structure in Bornean stream frogs. Journal of Animal Ecology 78:305-314.

KwET, A. 2007. Bioacoustic variation in the genus Adenomera in southern Brazil, with revalidation of Leptodactylus nanus Müller, 1922 (Anura: Leptodactylidae). Museum für Naturkunde Berlin Zoologisches 83:56-68.

Leite, P. F. 1990. Contribuição ao conhecimento fitoecológico do sul do Brasil. Ciência \& Ambiente 1(1):51-73.

LuCAS, E. M. \& ForTES, V. B. 2008. Frog diversity in the Floresta Nacional de Chapecó, Atlantic Forest of southern Brazil. Biota Neotropica 8(3):51-61.

MAACK, R. 1981. Geografia física do estado do Paraná. Rio de Janeiro, José Olympio. 450p.

Machado, I. F.; Moreira, L. F. B.; Silva, R. B.; Becker, R. G. \& Mesquita, A. S. O. 2010. Amphibia, Anura, Centrolenidae, Vitreorana uranoscopa (Müeller, 1924): Distribution extension in the state of Rio Grande do Sul, Brazil. Check List 6(3).

Machado, R. A.; Bernarde, P. S.; Morato, S. A. B. \& Anjos, L. 1999. Análise comparada da riqueza de anuros entre duas áreas com diferentes estados de conservação no município de Londrina, Paraná, Brasil (Amphibia: Anura). Revista Brasileira de Zoologia 19:9971004.

Marsh, D. M. 2001. Behavioral and Demographic Responses of Túngara Frogs to Variation in Pond Density. Ecology 82(5):1283-1292.

MMA - Ministério do Meio Ambiente. 2012. Cadastro Nacional de UC's. Disponível em <http://www.mma.gov.br/areas-protegidas/ cadastro-nacional-de-ucs/consulta-por-uc>. Acesso em: 14.12.2012.

Myers, N.; Mittermeier, R. A.; Mittermeier, C. G.; Fonseca, G. A. B. DA \& KENT, J. 2000. Biodiversity hotspots for conservation priorities. Nature 403:853-858.

NiLsson, L. A. 1988. The evolution of flowers with deep corolla tubes. Nature 334:147-149.

Nunes, I; Kwet, A. \& Pombal JR, J. P. 2012. Taxonomic Revision of the Scinax alter Species Complex (Anura: Hylidae). Copeia 2012(3):554569.

Pacheco, R. \& Vasconcelos, H. L. 2012. Habitat diversity enhances ant diversity in a naturally heterogeneous Brazilian landscape. Biodiversity Conservation 21:797-809.

PARRIS, K. M. 2004. Environmental and spatial variables influence the composition of frog assemblages in sub-tropical eastern Australia. Ecography 27:392-400.

Pearl, C. A.; Adams, M. J. \& Bury, R. B. 2004. Asymmetrical effects of introduced bullfrogs (Rana catesbeiana) on native ranid frogs in Oregon. Copeia 2004(1):11-20.

PiankA, E. R. 1994. Evolution ecology. New York, Harper Collins College Publishers.
Pilliod, D. S.; Hossack, B. R.; Bahls, P. F.; Bull, E. L.; Corn, P. S.; Hokit, G.; Maxwell, B. A.; Munger, J. C. \& Wyrick, A. 2010. Non-native salmonids affect amphibian occupancy at multiple spatial scales. Diversity and Distributions 16:959-974.

Pombal JR, J. P. \& HadDaD, C. F. B. 2005. Estratégias e modos reprodutivos de anuros (Amphibia) em uma poça permanente na Serra do Paranapiacaba, Sudeste do Brasil. Papéis Avulsos de Zoologia 45(15):201-213.

Pombal JR, J. P.; Haddad, C. F. B. \& Kasahara, S. 1995. A new species of Scinax (Anura: Hylidae) from southeastern Brazil, with comments on the genus. Journal of Herpetology 29:1-6.

Prado, C. P. A.; Uetanabaro, M. \& Haddad, C. F. B. 2005. Breeding activity patterns, reproductive modes, and habitat use by anurans (Amphibia) in a seasonal environment in the Pantanal, Brazil. Amphibia-Reptilia 26:211-221.

Ramos, F. N. \& Santos, F. A. M. 2006. Microclimate of Atlantic forest fragments: regional and local scale heterogeneity. Brazilian Archives of Biology and Technology 49:935-944.

Ricklefs, R. E. \& SChluter, D. 1993. Species diversity in ecological communities: historical and geographical perspectives. Chicago, University of Chicago Press. 414p.

Rio Negro. 2004. Plano de Manejo do Parque Ecoturístico Municipal São Luís de Tolosa. Prefeitura Municipal de Rio Negro, Paraná, Brasil. Vol. Único. CD.

Rocha, C. F. D.; Van Sluys, M.; Bergallo, H. G. \& Alves, M. A. S. 2005. Endemic and threatened tetrapods in the restingas of the biodiversity corridors of Serra do Mar and of the central da Mata Atlântica in Eastern Brazil. Brazilian Journal of Biology 65(1):159-168.

Roderjan, C. V.; Galvão, F.; Kuniyoshi, Y. S. \& Hatschbach, G. G. 2002. As unidades fitogeográficas do estado do Paraná, Brasil. Ciência \& Ambiente 24:78-118.

Santos, T. G.; Kopp, K.; Spies, M. R.; Trevisan, R. \& Cechin, S. Z. 2008. Distribuição temporal e especial de anuros em área de Pampa, Santa Maria, RS. Iheringia, Série Zoologia 98(2):244-253.

SCHLOSSER, I. J. 1995. Critical landscape atributes that influence fish population dynamics in headwater streams. Hydrobiologia 303:7181.

SCOTT JR, N. \& WoOdWARd, B. D. 1994. Surveys at breeding sites. p. 118125. In: Heyer, W. R.; Donnelly; M. A.; McDiarmid, R. W.; HayeK, L. C. \& Foster, M. C. eds. Measuring and Monitoring Biological Diversity - Standard Methods for Amphibians. Washington, Smithsonian Institution Press. 364p.

Segalla, M. V.; Caramaschi, U.; Cruz, C. A. G.; Garcia, P. C. A.; Grant, T.; HADDAD, C. F. B \& LANGONE, J. 2012. Brazilian amphibians - List of species. Disponível em: <http://www.sbherpetologia.org. br>. Acesso em: 30.09.2012.

Sgrillo, R. 2012. GE-Path: Google Earth Path v. 1.4.6. Disponível em: <http://www.sgrillo.net $>$. Acesso em: 14.12.2012.

SHAFFER, M. L. 1981. Minimum population sizes for species conservation. BioScience 31:131-134.

Silva, F. R.; Candeira, C. P. \& Rossa-Feres, D. C. 2012. Dependence of anuran diversity on environmental descriptors in farmland ponds. Biodiversity Conservation 21:1411-1424.

Silva, F. R. \& Rossa-Feres, D. C. 2007. Uso de fragmentos florestais por anuros (Amphibia) de área aberta na região noroeste do Estado de São Paulo. Biota Neotropica 7(2):141-148.

Silvano, D. L. \& Segalla, M. V. 2005. Conservação de Anfíbios no Brasil. Megadiversidade 1(1).

Silvano, D. L. \& Pimenta, B. V. S. 2003. Diversidade e distribuição de anfíbios na Mata Atlântica do Sul da Bahia. In: Prado, P. I.; LANDAU, E. C.; Moura, R. T.; Pinto, L. P. S.; Fonseca, G. A. B. \& Alger, K. orgs. Corredor de Biodiversidade na Mata Atlântica do Sul da Bahia. Ilhéus, IESB/CI/CABS/UFMG/UNICAMP. CD-ROM.

Stebbins, R. C. \& Cohen, N. W. 1995. A Natural History of Amphibians. New Jersey, Princeton University Press. 316p.

Toledo, L. F. \& HADDAD, C. F. B. 2003. Distribuição espacial e temporal de uma comunidade de anfíbios anuros do município de Rio Claro, São Paulo, Brasil. Holos Environment 3(2):136-149.

Vasconcelos, T. S. \& Rossa-Feres, D. C. 2005. Diversidade, distribuição espacial e temporal de anfíbios anuros (Amphibia, Anura) na região Noroeste do Estado de São Paulo, Brasil. Biota Neotropica 5(2). 
Vasconcelos, T. S.; Santos, T. G.; Rossa-Feres, D. C. \& Haddad, C. F. B. 2009. Influence of the environmental heterogeneity of breeding ponds on anuran assemblages from southeastern Brazil. Canadian Journal of Zoology 87:699-707.

Veloso, H. P.; Filho, A. L. R. R. \& Lima, J. C. A. 1991. Classificação da vegetação brasileira, adaptada a um sistema universal. Rio de Janeiro, IBGE, Departamento de Recursos Naturais e Estudos Ambientais. 124p.

Wellborn, G. A.; Skelly, D. K. \& Werner, E. E. 1996. Mechanisms creating community structure across a freshwater habitat gradient. Annual Review of Ecology and Systematics 27:337-363.

WeLLS, K. D. 2007. The ecology and behavior of amphibians. Chicago University Press. 1148p.

Werner, E. E.; Skelly, D. K.; Relyea, R. A. \& Yurewicz, K. L. 2007. Amphibian species richness across environmental gradients. Oikos 116:1697-1712.
Weyrauch, S. L. \& Grubb JR., T. C. 2004. Patch and landscape characteristics associated with the distribution of woodland amphibians in a agricultural fragmented landscape: an informationtheorectic approach. Biological Conservation 115:443-450.

Wogel, H.; Abrunhosa, P. A. \& Pombal JR, J. P. 2002. Atividade reprodutiva de Physalaemus signifer (Anura, Leptodactylidae) em ambiente temporário. Iheringia, Série Zoologia 92(2):57-70.

ZAR, J. H. 1999. Bioestatistical analysis. New Jersey, Prentice Hall. 663p.

Zimmerman, B. L. \& SimberlofF, D. 1996. An Historical Interpretation of Habitat Use by Frogs in a Central Amazonian Forest. Journal of Biogeography 23(1):27-46.

Zug, G. R.; Vitt, L. J. \& Caldwell, J. P. 2001. Herpetology: an introductory biology of amphibians and reptiles. v.2. San Diego, Academic Press.

Anexo 1. Espécimes coletados no Parque Municipal São Luís de Tolosa, Rio Negro, PR, Brasil entre setembro de 2008 e agosto de 2009, e número de registro no Departamento de Zoologia e Botânica de São José do Rio Preto (DZSJRP). Autor das coletas e do tombo: Carlos E. Conte. Aplastodiscus perviridis: 13501; Dendropsophus microps: 13500; Hypsiboas bischoff: 13450; Ischnocnema guentheri: 13403, 13445, 13514; Leptodactylus latrans: 13496, 13542; Adenomera nana: 13446, 13447, 13495; Odontophrynus americanus: 13448; Proceratophrys brauni: 13402, 13451, 13568, 13569; Rhinella abei: 13404; Scinax imbegue: 13499, 13570; Scinax perereca: 13449; Scinax rizibilis: 13452, 13453, 13454; Scinax sp. (gr. catharinae): 13399, 13400, 13401, 13497, 13498, 13515, 13516, 13541, 13573; Vitreorana uranoscopa: 13571, 13572.

Anexo 2. Parâmetros acústicos para as espécies novas do complexo Scinax alter (Lutz, 1973) descritas por NunEs et al. (2012) (d) e para espécie cujos parâmetros foram avaliados a partir de indivíduos ocorrentes no Parque Municipal São Luís de Tolosa, Rio Negro, PR (PSLT) (FDom, frequência dominante no canto; FMax, frequência máxima no canto; FMin, frequência mínima no canto). (*) Variável que não pôde ser analisada. ( \pm ) Desvio padrão. Valores de frequência em hertz.

\begin{tabular}{|c|c|c|c|c|c|c|c|}
\hline Espécie & $\begin{array}{l}\mathrm{N}^{\mathrm{o}} \text { de cantos } \\
\text { (indivíduos) }\end{array}$ & Duração do canto & Cantos/Seg & Pulsos/Canto & FDom & FMax & FMin \\
\hline $\begin{array}{l}\text { Scinax tymbamirim } \\
\text { (d) }\end{array}$ & $14(1)$ & $0,488( \pm 0,045)$ & $0,494( \pm 0,053)$ & $19( \pm 0,82)$ & $\begin{array}{c}4510,05 \\
( \pm 205,33)\end{array}$ & $\begin{array}{c}8294 \\
( \pm 163,34)\end{array}$ & $\begin{array}{c}1502 \\
( \pm 20,90)\end{array}$ \\
\hline $\begin{array}{l}\text { Scinax imbegue } \\
\text { (d) }\end{array}$ & $11(1)$ & $0,461( \pm 0,051)$ & $0,986( \pm 0,137)$ & $16( \pm 1,55)$ & $*$ & $6493( \pm 141,48)$ & $887( \pm 18,48)$ \\
\hline Scinax imbegue (PSLT) & $60(3)$ & $0,415( \pm 0,039)$ & $0,923( \pm 0,078)$ & $12,4( \pm 1,18)$ & $1296,62( \pm 7,75)$ & $\begin{array}{c}6018,2 \\
( \pm 29,38)\end{array}$ & $622( \pm 32,70)$ \\
\hline
\end{tabular}

Anexo 3. Cantos revisados de Scinax tymbamirim Nunes, Kwet \& Pombal Jr, 2012 e Scinax imbegue Nunes, Kwet \& Pombal Jr, 2012 analisadas por Nunes et al. (2012): a) oscilograma e b) sonograma de Scinax tymbamirim; c) oscilograma e d) sonograma de Scinax imbegue; e) oscilograma e f) sonograma de indivíduos de Scinax imbegue ocorrentes no Parque Municipal São Luís de Tolosa, Rio Negro, PR, Brasil.

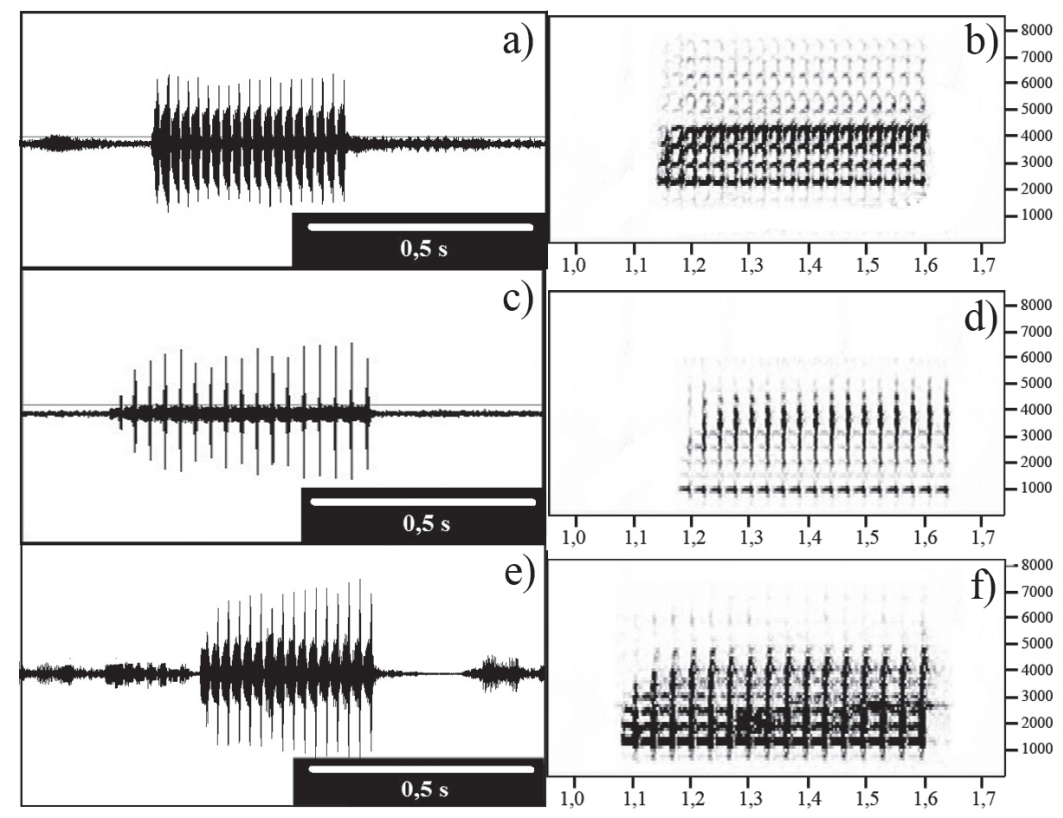

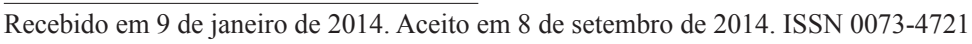

Artigo disponível em: www.scielo.br/isz 